\title{
The applicability of neuroscience to facilities management
}

Article Type: Editorial From: Journal of Facilities Management, Volume 12, Issue 1

A research field gaining increasing interest in recent years is the relationship between architecture and neuroscience. As different as these two fields may seem, Moustaka et al. (2012) argue that they share significant common ground. Architecture has traditionally been a bipolar discipline. On the one hand, the architect has to be a good engineer, designing sound buildings with comfortable conditions but on the other hand, is expected to produce interesting and aesthetically pleasing results. While he can scientifically justify the part of his work that deals with structure mechanics, or functionality, he may be unable to reason the way a building is perceived as that deals with a brain process that is difficult to quantify.

Moustaka et al. (2012) suggest that this is where neuroscience comes in. Where research was to be done into the way architecture affects our mood or our cognition, the social sciences were employed up until recently through the use of observation and questionnaires. However, even this kind of research is limited. For example, school building conditions were found to have a profound effect on the performance of pupils on tests, but the actual reason behind this was unknown (Durán-Narucki, 2008).

Several research projects have highlighted the importance of environmental settings. For example, in hospitals, views from windows have been found to influence disease outcomes and pain perceptions (Malenbaum et al., 2008) and the use of plants in offices can reduce absenteeism (Smith and Pitt, 2011). Natural environment views have been found to have a restorative function (Kaplan, 1993), aiding in stress recovery (Ulrich et al., 1991). Neuroscience offers the opportunity to further examine these findings, providing a method of decoding the brain processes involved.

It is through our senses that we perceive our surroundings, which means that architects have the ability to profoundly affect how we perceive and operate within facilities including workplaces, healthcare facilities, leisure environments and our own homes. However, it appears that little attempt has been made to understand how. Most of us have anecdotal experiences around how we feel in a particular building, although it can be difficult to pinpoint why. Neuroscience provides the opportunity to explore these reasons. This could be particularly pertinent to the sustainable design and use of facilities.

What does this mean for facilities managers? Most facilities managers understand, based on anecdotal evidence, that the workplace has a major effect on the workforce in terms of satisfaction and ultimately productivity and profitability of the organisation. Similarly, 
academics such as Haynes (2007) have been arguing for a more behavioural approach to facilities management for some time. However, this does not seem to be widely accepted at the corporate level (Smith and Moustaka, 2012).

Smith and Moustaka (2012) argue that a greater focus of attention on human factors is required in facilities design and service provision, first to enable a deeper understanding of the issues at play and second, to elevate the FM profession to greater heights of recognition of the role it can play at the strategic level. Social aspects and the impact of architecture on neuroscience are emerging areas that may provide valuable insights.

The emerging field of neuroscience offers the designer an additional knowledge pool to examine ways of approaching human comfort and energy consumption and a possibility for the facilities manager to improve environmental conditions without resorting to intricate technologies. Through further research in this important area, we will be able to gain further insight into the workings of the brain in relation to the buildings we use (Smith and Moustaka, 2012). There is massive potential in the field of neuroscience and its application to built environment research. Overall, a more holistic approach to the integration of built environment professions is perhaps required, drawing upon the knowledge of seemingly separate professions or research areas and applying this to the entire lifecycle of a facility.

\section{Andrew Smith}

\section{References}

Durán-Narucki, V. (2008), "School building condition, school attendance, and academic achievement in New York city public schools: a mediation model $\square$, Journal of Environmental Psychology, Vol. 28 No. 3, pp. 278-286

Haynes, B. (2007), "The impact of the behavioural environment on office productivity $\square$, Journal of Facilities Management, Vol. 5 No. 3, pp. 158-171

Kaplan, R. (1993), "The role of nature in the context of the workplace $\square$, Landscape and Urban Planning, Vol. 26 Nos 1-4, pp. 193-201

Malenbaum, S., Keefe, F., Williams, A., Ulrich, R. and Somers, T. (2008), "Pain in its environmental context: implications for designing environments to enhance pain control $\square$, Pain, Vol. 134 No. 3, pp. 241-244 
Moustaka, A., Smith, A. and Akintoye, A. (2012), "Towards an anthropocentric approach in sustainability research $\square$, paper presented at the EuroFM Conference, Copenhagen, Denmark, May

Smith, A. and Moustaka, A. (2012), "Neuroscience: an emerging field in facilities management? $\square$, Essential FM Report No. 99, January/February

Smith, A. and Pitt, M. (2011), "Healthy workplaces: plantscaping for indoor environmental quality $\square$, Facilities, Vol. 29 Nos 3/4, pp. 169-187

Ulrich, R.S., Simons, R.F., Losito, B.D., Fiorito, E., Miles, M.A. and Zelson, M. (1991), "Stress recovery during exposure to natural and urban environments $\square$, Journal of Environmental Psychology, Vol. 11 No. 3, pp. 201-230 